\title{
Digital business ecosystem: literature review and a framework for future research
}

Article

Accepted Version

Creative Commons: Attribution-Noncommercial-No Derivative Works 4.0

Senyo, P. K., Liu, K. and Effah, J. (2019) Digital business ecosystem: literature review and a framework for future research. International Journal of Information Management, 47. pp. 52-64. ISSN 0268-4012 doi:

https://doi.org/10.1016/j.jinfomgt.2019.01.002 Available at https://centaur.reading.ac.uk/81584/

It is advisable to refer to the publisher's version if you intend to cite from the work. See Guidance on citing.

To link to this article DOI: http://dx.doi.org/10.1016/j.ijinfomgt.2019.01.002

Publisher: Elsevier

All outputs in CentAUR are protected by Intellectual Property Rights law, including copyright law. Copyright and IPR is retained by the creators or other copyright holders. Terms and conditions for use of this material are defined in the End User Agreement.

www.reading.ac.uk/centaur 
Central Archive at the University of Reading

Reading's research outputs online 


\title{
Digital business ecosystem: literature review and a framework for future research
}

\begin{abstract}
Digital innovation has radically changed how organisations collaborate and compete. Coupled with this change are new collaborative value creation networks such as digital business ecosystems (DBEs). DBE is a socio-technical network of individuals, organisations and technologies that collectively co-create value. Since the emergence of DBE over a decade ago, there have been limited attempts to critically review and synthesise the body of knowledge presented over the years. Thus, the purpose of this paper is to fill this gap in DBE research by: (1) developing a comprehensive framework that synthesises and provides an overall direction of DBE research; (2) pointing out gaps in DBE literature; and (3) providing future research directions. To address this purpose, we systematically analysed 101 research articles on DBE. The findings provide insightful revelations to address some limitations in the current DBE research. As such, this study makes important contributions and serves as a useful resource for future DBE studies and practice.
\end{abstract}

Keywords: digital business ecosystem (DBE), systematic literature review, framework, future research, grounded theory

\section{Introduction}

The advancement of digital technology has led to the development of new collaborative organisational networks such as digital business ecosystem (DBE). DBE is a collaborative environment made up of different entities that co-create value through information and communication technologies (ICTs) (Nachira, Dini, \& Nicolai, 2007). DBE transcends traditional industry boundaries to foster open and flexible collaboration and competition. For many organisations, DBE presents an innovative approach to leverage resources such as technology and specialised services across different industries to respond to customer needs.

Since its conceptualisation from a European Union (EU) project (Whitley \& Darking, 2006), DBE has gained popularity in many disciplines such as information systems (IS) (e.g., Graça \& Camarinha-Matos, 2017; Senyo, Liu, Sun, \& Effah, 2016; Tsatsou, Elaluf-calderwood, \& Liebenau, 2010), general management (e.g., Koch and Windsperger, 2017), tourism (e.g., Del Chiappa \& Baggio, 2015) and computer science (e.g., Hussain, Chang, Hussain, \& Dillon, 2007a). In practice, DBE has also gained increasing attention (Gartner, 2015) as organisations strive to leverage external resources to meet growing customer needs. Therefore, to push DBE research forward, it is important to review the extant studies to unearth: (1) extensively researched issues, (2) less-researched areas, (3) methods and theories used in prior research, as well as (4) issues for future studies.

In the extant IS literature, limited attempts have been made to systematically review DBE studies. Thus, we argue that a thorough review of existing literature on DBE will: (1) enable proper evaluation to determine the extent of studies already undertaken and offer gaps for future studies; and (2) support better understanding of the DBE concept and stimulate future 
research. Therefore, this study seeks to provide a critical review of DBE research by synthesising existing studies and developing a framework that highlights issues, methodologies and methods as well as theories in prior investigations. The main research questions motivating this study are:

RQ1: What themes have been investigated in prior DBE research?

RQ2: What methodologies and methods have been utilised in the extant DBE research?

RQ3: What theories, models and frameworks have informed prior DBE research?

RQ4: What gaps exist in current DBE research that future studies can investigate?

To address these research questions, the rest of this paper is organised as follows. First, we present an overview of the DBE concept. Next, we discuss our research method in terms of journal selection, literature search, article selection, refinement and analysis approaches. Thereafter, we present the findings to address our research questions. This is followed by presentation of our proposed DBE research framework, which we consider useful for future research and practice. Finally, we conclude the paper with a discussion of our research contributions.

\section{Overview of Digital Business Ecosystem}

DBE is an extension of Moore's (1993) business ecosystem for which digital technology plays a dominant role. The birth of business ecosystem was motivated by cross-industry operation analogous to the biological ecosystem ( $\mathrm{Li}, 2009)$. Business ecosystem is an economic community of loosely-coupled interacting organisations and individuals who produce valuable goods and services (Moore, 1993). While business ecosystem portrays generic organisational interdependence, DBE extends this concept by placing more importance on the centrality of digital technology.

DBE comprises two main tiers: digital (ecosystem) and business (ecosystem) (Stanley \& Briscoe, 2010). Digital ecosystem refers to a virtual environment populated by digital entities such as software applications, hardware and processes (Nachira et al., 2007). Digital ecosystem operates as a peer-to-peer distributed technology infrastructure that creates, disseminates and connects digital services over the Internet. On the other hand, business ecosystem is an economic community of individuals and organisations that operate outside their traditional industry boundaries (Moore, 1993). Thus, in this study, we define DBE as a socio-technical environment of individuals, organisations and digital technologies with collaborative and competitive relationships to co-create value through shared digital platforms.

DBE is multifaceted; as such, it can be viewed as a concept, a technology or a project (Darking \& Whitley, 2007). As a concept, DBE acknowledges the role of digital technology infrastructure and network of entities in value co-creation. DBE as a technology refers to a distributed computing infrastructure that provides capabilities for small and medium-sized enterprises (SMEs) to compete globally (Herdon, Várallyai, \& Péntek, 2012). Lastly, DBE as a project refers to a research programme that investigates and develops tools to support organisations to collaborate and compete globally through ICT. An example of a DBE project is the EU's 2003 DBE research programme. 
In DBEs, co-created value is presumed to be greater than that created by a single organisation (Adner, 2006). Value co-creation involves efforts and resources from different entities towards value creation (Prahalad \& Ramaswamy, 2004). Value is defined as financial or nonfinancial benefits derived from interactions between entities (Vargo, Maglio, \& Akaka, 2008). As a result, value can be realised from appropriate combination of low cost, faster processes and high quality services. In the traditional business environment, organisations are seen as the sole creators of value. However, in the contemporary business setting, value cocreation occurs through collective efforts of organisations, their partners and customers (Chuang \& Lin, 2015). Given that DBE relies on synergy between different entities to generate value, we see value co-creation as an important driver in DBE formation and operation.

The main characteristics of DBEs are platform, symbiosis, co-evolution and self-organisation (Senyo, Liu, \& Effah, 2018). Platform refers to a collection of tools, innovations and services that other DBE partners can use to enhance their performance, create innovations and collaborate (Selander, Henfridsson, \& Svahn, 2013). DBE platform consists of computer hardware, software systems and networks. Thus, a DBE platform can take the form of a tangible computer hardware system such as Apple's iPhone or an intangible computer software form as the App Store. It is also important to note that there could be more than one platform in a DBE. Symbiosis refers to interdependence between DBE partners, processes and technologies (Senyo, Liu, \& Effah, 2017). Symbiosis leads to synergy between entities to co-create greater value. According to Adner (2006), no single organisation can create value which supersedes that of an ecosystem. Hence, it is important for organisations to interdepend to blend their strengths and weaknesses for greater value proposition.

Co-evolution refers to the ability of a DBE to collectively transform with its partners from one stage to another (Moore, 1996; Senyo et al., 2018). When changes arise in a DBE because of opportunities or threats, key partners dynamically react while other interdependent partners also adapt to the changes. The co-evolutionary characteristics differentiate DBE from other organisational networks where some individual organisations transform without others. Self-organising refers to the ability of DBEs to learn from their environment and accordingly respond (Peltoniemi, 2006). Due to complexities in relationships, DBEs learn and autonomously evolve as new requirements, opportunities and threats emerge. As a result, DBEs are generally dynamic.

Finally, DBE is a class of collaborative networks with a wider alliance of heterogenous and geographically dispersed entities that collaborate via the Internet to achieve common outcomes (Camarinha-Matos \& Afsarmanesh, 2008). Collaborative networks consist of two main categories of relationships, namely organised and ad-hoc collaborations (Graça \& Camarinha-Matos, 2017). Organised collaborations consist of long-term strategic relationship networks. On the other hand, ad-hoc collaborations are short-term, task-specific alliances which may terminate after fulfilling intended goals (Camarinha-Matos \& Afsarmanesh, 2008). In addition to the organised and ad-hoc collaborations, DBEs are also characterised by competitive relationships. 


\section{Methods}

Following, Senyo, Addae and Boateng (2018), we used systematic literature review and combined it with Wolfswinkel et al.'s (2013) grounded theory literature review method. While systematic literature review offers a pre-defined procedure for literature search and refinement, the grounded theory literature review method ensures extraction of linkages between different papers. The two approaches were chosen to achieve a holistic literature coverage, adequate extraction of meanings and associations between studies as well as thorough analysis. In line with these approaches, we followed a five-stage systematic review process (see Figure 1): (1) definition of literature inclusion and exclusion criteria, (2) literature search, (3) literature refinement, (4) analysis of selected articles and (5) presentation of findings. The discussions below elaborate on each of these stages and their sub components.

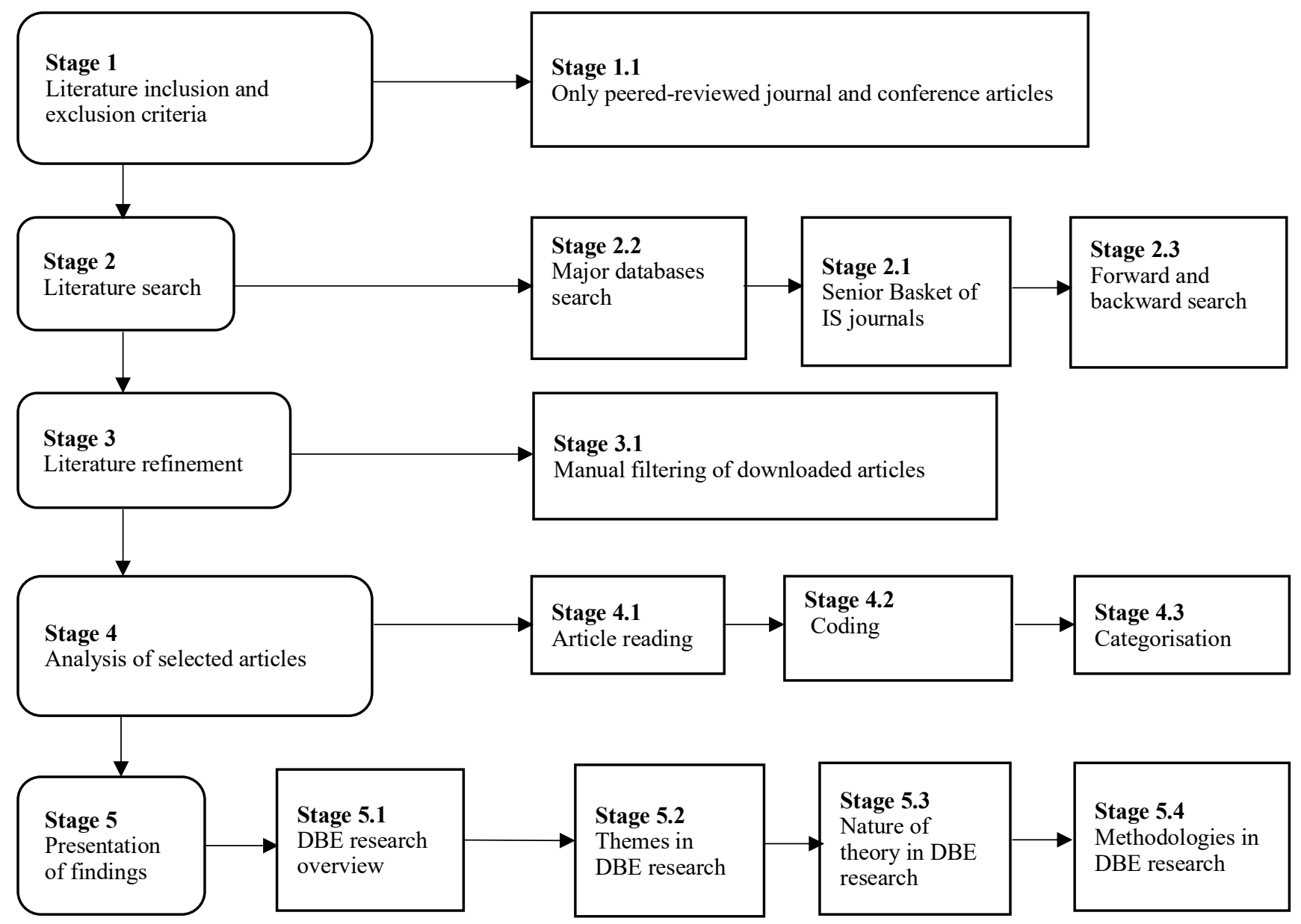

Figure 1. A five stage systematic literature review process

\subsection{Definition of literature inclusion/exclusion criteria}

We set out to ensure a quality review. As such, our literature inclusion criteria were targeted at papers from high-quality sources. We agree with Webster and Watson (2002) that highquality contributions in a field are predominantly found in reputable sources such as academic journals and conferences. Therefore, we included only peer-reviewed journal and conference articles and excluded dissertations, books reviews, case studies and books. We 
defined our search terms as "digital business ecosystem", "DBE", "digital ecosystem", "business ecosystem" and "collaborative network" to capture both DBE and related articles.

\subsection{Literature search}

To ensure a complete coverage, we started the literature search from 12 major databases, namely ABI/INFORM, ACM Digital Library, AISeL, Emerald journals, IEEE Xplore Digital Library, EBSCOhost, SAGE, Science Direct, Scopus, Springer Link, Web of Science and Wiley Online Library. We chose these databases because they cover a significant range of IS journals and conference publications (Webster \& Watson, 2002). In addition, we searched the Senior Scholars' Basket of IS journals individually to ensure that the leading journals within the IS field were included. Using the defined terms, we conducted the search on the titles, keywords and abstracts. Finally, we conducted forward and backward searches to ensure a holistic coverage of the articles sampled. Specifically, we manually reviewed the reference list of the sampled articles during the backward searches. Using the Google Scholar search engine, we filtered the references of each selected paper during the forward search. In the end, a total of 303 peer-reviewed journal and conference articles were collated for further refinement and analysis.

\subsection{Literature refinement}

Given that the articles sampled included duplicates and studies on related DBE concepts, we conducted further refinement. At this stage, we carefully filtered the sampled articles for duplicates and discarded those that did not meet the inclusion criteria. We performed the literature refinement process by reading the title, abstract and the main text of the sampled articles. We discarded articles that only used DBE as an example, a reference to explain other concepts or listed DBE as a keyword without further discussion in the main text. After manually refining the sampled literature, a total of 101 journal and conference articles were selected for analysis in this review.

\subsection{Analysis of selected literature}

At this stage, we assigned codes to the selected articles based on DBE research themes, methodologies, theories and gaps for future research. For the DBE research themes, we applied the tenets of grounded theory literature review method (Wolfswinkel et al., 2013). Specifically, we read individual papers and developed open codes in the first instance. From this analysis, we developed 71 open codes. Next, we analysed conceptual similarities of the open codes to generate axial codes. As a result, we developed 19 axial codes. Finally, after continuous iterative analysis through mapping and integrating as well as refining of the axial codes (Corbin \& Strauss, 1990), we developed 4 selective codes as the main themes in DBE research.

With regards to analysis on theory and research methodology, we coded the selected articles based on their underpinning theoretical lens and methodologies. A master classification table was developed in Microsoft Word for excerpts, notes and categories from each article. For instance, in coding the article by Tsatsou et al., (2010), excerpts such as risk and trust, jurisdiction and consumer protection, governance and regulation as well as e-signature and security were derived as the open codes. We also classified the paper under the business 
issues selective code since the focus of the paper was to address the role of trust and regulation among entrepreneurs participating in the DBE project in Europe. In terms of research methodology, the article was coded under the qualitative methodology since it used the historical case study as a research approach. Since the paper did not utilise any mainstream theory, it was coded under the "no theory" category. However, in terms of gaps for future studies, the paper was coded under DBE "governance, regulation and security" issues.

\section{Results}

In this section, we present the findings of the literature reviewed under the following subsections: (1) overview of DBE research, (2) themes in DBE research, (3) research methodologies and methods in DBE research and (4) theories used in DBE research.

\subsection{Overview of DBE research}

This subsection presents the distribution of publications by journal and conference sources as well as yearly trends. Table 1 shows the distribution of DBE articles in journals and conferences. From the results, the IEEE Transactions on Industrial Electronics Journal recorded the highest number of publications with $4.95 \%$ in the journals category. The Journal of Information Technology followed with $1.98 \%$ while the remaining journals each recorded $0.99 \%$.

In terms of conference publications, the International Conference on Digital Ecosystems and Technologies had the highest representation of $37.62 \%$, followed by the PRO-VE conference with 11.88\%. The International Conference on Management of Digital EcoSystems had $4.95 \%$ while the International Conference on Information Systems had 3.96\%. The Hawaii International Conference on System Sciences had 2.97\% while the International Conference on Emerging Technologies and Factory Automation and the International Conference on Informatics and Semiotics in Organisations both recorded $1.98 \%$. The remaining conferences each recorded $0.99 \%$.

From this result, it is evident that there are limited journal publications on DBE research while the majority of the articles are conference papers. The substantial number of conference publications $(76.26 \%)$ can be attributed to the establishment of two main conferences dedicated to DBE research. Thus, it is not surprising that there are more conference papers than journal articles on DBE. While this initiative is laudable and demonstrates a phenomenal interest in DBE research, there is a need for corresponding journal publications.

Table 1 Article distribution based on journal and conference sources

\begin{tabular}{lcc}
\hline Journal and conference outlets & Count & Percentage \\
\hline Journals & 1 & 0.99 \\
\hline $\begin{array}{l}\text { Communications Law - Journal of Computer, Media and } \\
\text { Telecommunications Law }\end{array}$ & 1 & 0.99 \\
\hline Computers in Industry & 1 & 0.99 \\
\hline Data and Knowledge Engineering & 1 & 0.99 \\
\hline Expert Systems with Applications & & \\
\hline
\end{tabular}




\begin{tabular}{|c|c|c|}
\hline IEEE Transactions on Industrial Electronics & 5 & 4.95 \\
\hline Information Technology and Tourism & 1 & 0.99 \\
\hline International Journal of Integrated Supply Management & 1 & 0.99 \\
\hline Journal of Destination Marketing \& Management & 1 & 0.99 \\
\hline Journal of Information Technology & 2 & 1.98 \\
\hline Journal of Intelligent Manufacturing & 1 & 0.99 \\
\hline Journal of Organization Design & 1 & 0.99 \\
\hline Journal of Systems and Information Technology & 1 & 0.99 \\
\hline Knowledge Management Research \& Practice & 1 & 0.99 \\
\hline Science Studies & 1 & 0.99 \\
\hline Computational finance and its applications & 1 & 0.99 \\
\hline Procedia Manufacturing & 1 & 0.99 \\
\hline Coordination, Organizations, Institutions and Norms in Agent Systems II & 1 & 0.99 \\
\hline International Journal of Business Process Integration and Management & 1 & 0.99 \\
\hline International Journal of Knowledge-Based Development & 1 & 0.99 \\
\hline Americas Conference on Information Systems & 1 & 0.99 \\
\hline Annual Conference on Privacy, Security and Trust & 1 & 0.99 \\
\hline BLED e-Conference & 1 & 0.99 \\
\hline European Conference on Information Systems & 1 & 0.99 \\
\hline European and Mediterranean Conference on Information Systems & 1 & 0.99 \\
\hline Hawaii International Conference on System Sciences & 3 & 2.97 \\
\hline International Conference on Information Systems & 4 & 3.96 \\
\hline Information Security for South Africa & 1 & 0.99 \\
\hline $\begin{array}{l}\text { International Conference on Complex, Intelligent and Software Intensive } \\
\text { Systems }\end{array}$ & 1 & 0.99 \\
\hline International Conference on Digital Ecosystems and Technologies & 38 & 37.62 \\
\hline International Conference on Emerging Technologies and Factory Automation & 2 & 1.98 \\
\hline International Conference on Informatics and Semiotics in Organisations & 2 & 1.98 \\
\hline International Conference on Internet and Web Applications and Services & 1 & 0.99 \\
\hline International Conference on Management of Digital EcoSystems & 5 & 4.95 \\
\hline International Conference on Services Computing & 1 & 0.99 \\
\hline International Conference on Systems and Computer Science & 1 & 0.99 \\
\hline International Conference on Cybernetics and Intelligent Systems & 1 & 0.99 \\
\hline \multirow[t]{2}{*}{ PRO-VE } & 12 & 11.88 \\
\hline & 101 & 100 \\
\hline
\end{tabular}

In terms of year of publication, the findings show mixed results. Figure 2 shows the distribution of articles from the year 2006 to 2017. The years 2007, 2008, 2010, 2009, 2013 and 2016 recorded the highest number of publications represented by 25, 13, 13, 9, 8 and 7 articles respectively. The years 2017 and 2014 recorded 6 articles each while the year 2011 recorded 5 articles. Finally, the years 2006, 2012 and 2015 recorded 4, 3 and 2 articles 
respectively. A closer look at the results indicates more publication during the funding period of the EU DBE project. However, some years after the completion of the EU DBE project, there is reduced publications. Thus, for DBE research to develop into a mainstream research field, there is a need for more projects to support continuous interest.

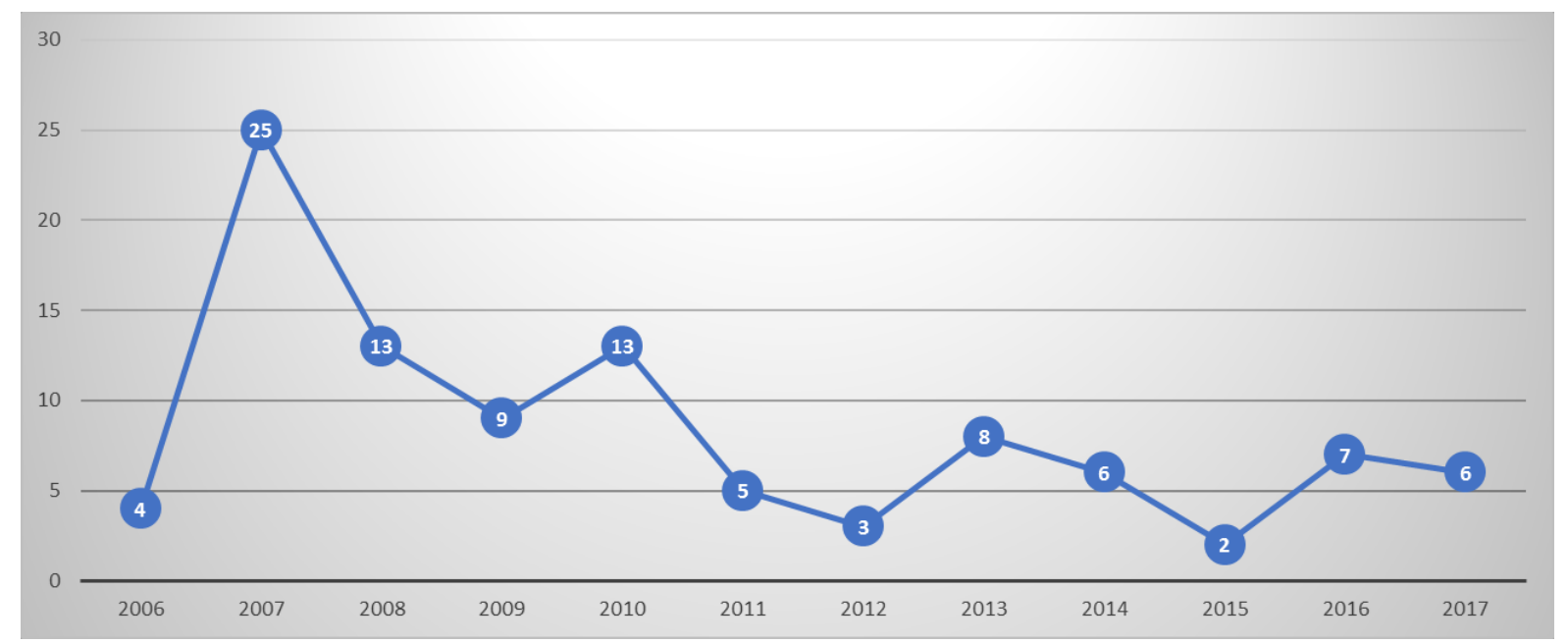

Figure 2. Article distribution by year of publication

\subsection{Themes in DBE research}

This subsection addresses the study's research question 1 (RQ1). As presented in Table 2, DBE research can be classified into 4 main themes (see selective codes), namely business issues, technical issues, DBE conceptualisation and DBE artefacts. The business issues theme consists of 25 open and 7 axial codes while the technical issues theme contains 18 open and 5 axial codes. The DBE conceptualisation theme has 9 open and 3 axial codes. Lastly, the DBE artefacts theme consists of 19 open and 4 axial codes. Each theme identified is further discussed as follows.

Table 2 DBE research themes

\section{Themes in DBE research}

Selective codes

Business issues
Axial codes

DBE alliances

Network analysis

Value co-creation

DBE governance and legal issues

Trust, risk and security

Knowledge development, dissemination and management DBE strategies and process management

Open codes
Knowledge development and dissemination
Technology platform impact
Boundary-spanning
Stakeholder relationships
Physical and virtual relationships
Technology transfer
DBE sustainability
DBE governance and regulations
DBE engagement practices
E-readiness and capability assessment
Trust and risk determination
DBE strategies
Value creation
Competitive advantage
Business process requirement
Disruptive transformation
Business intelligence
Resource sharing
Enterprise agility




\begin{tabular}{|c|c|c|}
\hline & & $\begin{array}{l}\text { Inter-network competition } \\
\text { DBE adoption } \\
\text { Privacy and consumer protection } \\
\text { E-contracts and security } \\
\text { DBE behaviour } \\
\text { Process management }\end{array}$ \\
\hline \multirow[t]{18}{*}{ Technical issues } & DBE platform design & Platform design process \\
\hline & DBE process and service design & DBE architecture \\
\hline & DBE technologies & DBE components \\
\hline & DBE architecture & DBE infrastructure maintenance \\
\hline & DBE systems integration and & Service negotiation \\
\hline & interoperability & Recommender systems \\
\hline & & DBE agent interaction modelling \\
\hline & & DBE prototyping \\
\hline & & DBE system integration \\
\hline & & Distributed agent systems \\
\hline & & Network topology \\
\hline & & DBE performance analysis \\
\hline & & Service-oriented architecture \\
\hline & & Enterprise architecture \\
\hline & & DBE systems interoperability \\
\hline & & DBE technologies \\
\hline & & Multi-agent systems \\
\hline & & Autonomic monitoring \\
\hline \multirow[t]{9}{*}{ DBE Conceptualisation } & DBE development and management & DBE formation and emergence \\
\hline & DBE projects & DBE properties \\
\hline & DBE genesis and properties & DBE overview \\
\hline & & DBE implementation \\
\hline & & DBE building blocks \\
\hline & & DBE project \\
\hline & & DBE life cycle \\
\hline & & DBE evolution \\
\hline & & DBE application \\
\hline \multirow[t]{19}{*}{ DBE artefact } & DBE methodologies & Process interoperability framework \\
\hline & DBE frameworks & DBE formation methodology \\
\hline & DBE models & Trust failure detection methodology \\
\hline & DBE modelling languages & DBE integration framework \\
\hline & & Situation retrieval model \\
\hline & & Agent interaction modelling methodology \\
\hline & & DBE process model for enterprise agility \\
\hline & & $\begin{array}{l}\text { Framework for inter sensing enterprise } \\
\text { architecture }\end{array}$ \\
\hline & & Reliability transaction processing framework \\
\hline & & Feedback ontology framework \\
\hline & & Negotiation language open metamodel \\
\hline & & e-loyalty conceptual framework \\
\hline & & Trust Model \\
\hline & & $\begin{array}{l}\text { Query meta-model language design and } \\
\text { imnlementation }\end{array}$ \\
\hline & & Simulation framework \\
\hline & & Dynamic integration framework \\
\hline & & Coordination model \\
\hline & & DBE negotiation framework \\
\hline & & Business modelling language \\
\hline
\end{tabular}




\section{Business issues theme}

Studies within the business issues theme focus on commercial implications of DBE. Specifically, these articles examine how DBEs generate business value for participants. The axial codes under the business issues theme as presented in Table 2 are DBE alliances, network analysis, value co-creation, DBE governance and legal issues, trust, risk and security, knowledge development, dissemination and management, as well as DBE strategies, processes and management.

Studies on DBE alliances investigate how relationships are formed between partners and subsequently developed into matured digitally enabled networks. At the core of these studies are issues on stakeholder relationship management (Selander, Henfridsson, \& Svahn, 2010), boundary spanning (Tan et al., 2016), resource sharing (Petrou \& Giannoutakis, 2009) and enterprise agility (Tan et al., 2009). While business alliance has been investigated over the years, studies from DBE present alternative issues that are not well established in the literature. Some of these issues include how to develop agility through technology, which technological resources should be open to partners and how to create "win-win" relationships through digital technologies. In effect, combining insights from DBE studies and existing knowledge on business alliance can open new avenues to examine organisational relationships holistically.

Studies on network analysis assess the underlying issues of exchanges between entities in DBEs. In these studies, the focus is on analysing physical and virtual ties among DBE entities to determine their relationship strength, network stability and robustness (Baggio \& Del Chiappa, 2014; Del Chiappa \& Baggio, 2015). With this analysis, the resilience of a DBE can be assessed to determine whether it can withstand disruptions (Burford \& Resmini, 2017). Given that DBE is a network of interdependencies that can be useful or detrimental, it is important for focal firms to have a good understanding of the overall status of their relationships (Fayoumi, 2016). As DBEs are socio-technical environments, it is important to understand the underlying issues of exchanges between entities. Thus, findings from the network analysis studies reaffirm the importance of exchanges in interdependent networks.

Similarly, articles on value co-creation in DBEs focus on how partners collectively generate value. In these studies, issues identified as essential for value co-creation in DBEs include ereadiness (Herdon et al., 2012), capability assessment (Sun et al., 2016), value creation processes (Selander et al., 2010) and inter-network competitions (Tan et al., 2009). So far, in the value co-creation literature, the focus has been on customer engagement (e.g., Acharya, Singh, Pereira, \& Singh, 2018; Kamboj, Sarmah, Gupta, \& Dwivedi, 2018). Thus, the findings from the articles reviewed offer additional insights not pronounced in the value cocreation literature. For instance, Sun et al.'s (2016) study on capability assessment in value co-creation offers a new perspective on how to strategically select new DBE partners. The study proposed a model to balance the strengths and weaknesses of a new partner with existing ones so that admission of the new actor does not result in weakening the entire DBE. Since the focus of value co-creation research has largely been on interactions with customers, we consider the issues investigated within the value co-creation sub-theme critical to unearthing unexplored aspects of value co-creation. 
Another key sub-theme under the business issues theme is DBE governance and legal concerns. Given that DBE is self-organising, it is sometimes difficult to define a specific governance structure. As such, related studies focus on how flexible governance approaches can be designed and implemented in DBEs (Darking, Dini, \& Whitley, 2006; Tsatsou et al., 2010). In addition, the geographical independence attribute of DBE creates a lacuna about relevant laws enforceable in legal issues (Chou, Lin, \& Huang, 2016). To address the issue of governance, Tsatou et al. (2010) for instance, investigate the interplay between trust and regulation in a DBE among entrepreneurs in the EU. Their study proposes a taxonomy of mechanisms to simplify regulatory requirements, norms and standards to eliminate conflicts. The issue of governance is prevalent due to the self-organising structure of DBE, which does not seem require an external regulator to function effectively. This situation creates a dilemma for participants as to how conflicts can be resolved. While the insights from existing studies are valuable, we see these contributions as the first steps towards a wider debate on DBE governance and legislative requirements.

In the same vein, some studies under the business issues theme expressed concerns over trust, risk and security in DBEs. These concerns are largely fuelled by the virtual nature of DBE transactions where physical contact between transacting parties is limited. As such, issues of trust, risk and security are key concerns for DBE participants (Hussain, Chang, Hussain, \& Dillon, 2007b). The constant highlight of these challenges in DBE research has led some studies to provide specific methodologies as remedy mechanisms for risk and trust (e.g., Hussain et al., 2007b; 2007c). While security concerns are always associated with digital innovations, DBE presents a unique case due to its value co-creation processes which require integration and sharing of critical business information with collaborators and competitors. Considering the extent of digitalisation in DBE and the need to address trust risk and security issues, we consider insights from this sub-theme critical.

DBE innovations can be derived from different sources. However, how to systematically develop, disseminate and manage innovative knowledge is challenging. Thus, some DBE studies (e.g., Attour and Peruta, 2014; Raza et al., 2009) examine knowledge creation, dissemination, and management processes to foster continuous innovation. Compared to innovation management in a single organisation, innovation generation in DBE requires complex interactions between heterogeneous entities. Currently, there is limited knowledge on standardisation of innovation management processes in DBEs. Thus, recommendations from extant studies include design of platforms to facilitate knowledge transfer (Pappas, Kazasis, Anestis, Gioldasis, \& Christodoulakis, 2007), and use of social media to aid stakeholders' involvement in knowledge management activities (Presenza, Micera, Splendiani, \& Del Chiappa, 2014) are considered important additions to knowledge.

Lastly, studies on DBE strategies and process management (e.g., Korpela et al., 2016; 2017) focus on measures participants can take to leverage and integrate emerging digital technologies into their processes to achieve competitiveness. Also, these studies highlight how DBE platforms should strategically be controlled (Koch \& Windsperger, 2017). For instance, some of these studies provide insights into which platform layers to open to others and how to manage inherent processes. Nevertheless, the insights from the studies do not 
clearly distinguish between DBE maturity stages and associated implementation strategies. Since all DBEs do not have the same maturity level, it is critical to understand appropriate strategies for each development stage.

\section{Technical issues theme}

The technical issues theme categorises studies that focus on the technological details of DBE. The axial codes under the technical issues theme are DBE platform design, DBE process and service design, DBE technologies, DBE architecture as well as DBE systems integration and interoperability.

Studies on DBE platform design examine how platforms emerge. It is posited that most platforms start as supply chain systems and gradually evolve into DBE platforms due to complementary efforts from other actors (Attour \& Peruta, 2014). DBE platform design studies further highlight the need for platforms to create conducive environments that reinforce reciprocating behaviour (Tan et al., 2016). Though existing platform design studies contribute critical insights, there are still outstanding issues such as platform development strategies, business and technical considerations as well as sustainability elements. Currently, studies on DBE platform design (e.g., Marcon et al., 2008; Ndou et al., 2010) are for specific projects, and are therefore less generic. Hence, knowledge of these design processes is difficult to generalise to other platform designs. Also, in the extant literature, platform design studies are mostly focused on technology context while less is known about non-ICT domains such as agriculture, education and community activism.

Similarly, the DBE process and service design sub-theme includes articles that target how DBE processes and services are designed in platforms to support value co-creation. Given that DBE services are often virtual, issues of key consideration include service negotiation processes (De La Rosa et al., 2011), multi-agent system interaction (Wang, De Wilde, \& Wang, 2009) and service-oriented architecture (Adil, Saqib, \& Fei, 2007). For instance, De La Rosa et al. (2011) investigate how agents negotiate on behalf of small organisations through an open negotiation environment platform in a DBE. The platform allows agents to use ecosystem services to develop new technologies on behalf of agents. With the platform, new services such as ecosystem monitor, and negotiation style recommender are developed to support stability for small organisations. While the insights from these studies are useful, there is still the issue of standardisation for easy migration of DBE processes and services from one platform to another (Figay, Ghodous, Khalfallah, \& Barhamgi, 2012).

Studies in the DBE technologies sub-theme examine how technical innovations such as recommender systems, autonomic monitoring, collective intelligence and data mining techniques support DBEs' developments and operations (De La Rosa et al., 2011). In particular, these studies stress the need for standardization of DBE technologies to foster seamless interoperability between systems (Korpela et al., 2017). Suggestions from these studies that are DBE technologies should enable partner recommender systems that create virtual organisations for SMEs to join forces with multinational firms to undertake large projects. As an emerging innovation, DBE design depends on existing technologies. However, no clear protocols exists on levering technologies to transform organisations 
virtually. As a result, organisations planning to form new DBEs struggle due to lack of clear guidelines.

The DBE architecture sub-theme includes studies that propose new approaches for defining the structure of technical and software components (Cheah, 2007). The key recommendation is the need to develop a DBE oriented architecture instead of relying on existing approaches, which lack the capability to deal with specific requirements such as multi-tenancy, selforganising and autonomous platform optimisation (Fischer, Scholten, \& Scholten, 2010). Despite this admonishment, some existing DBE architectures such as FISEA (Vargas, Cuenca, Boza, Sacala, \& Moisescu, 2016) and PANDA solution architecture (Svirskas, Ignatiadis, \& Briggs, 2008) are still based on the principles of the service-oriented architecture. In addition, these architectures are still conceptual and not rigorously validated empirically. Thus, we will argue for DBE architecture designs to use useful aspects of existing methodologies instead of wholly discarding them. Again, rigorous empirical validation is needed for developed DBE architectures.

Lastly, studies in the DBE systems integration and interoperability sub-theme focus on how DBE objects can be seamlessly combined. In particular, these studies stress the need for critical attention to business-related issues since technology integration is not the biggest problem (Korpela et al., 2017). Given that DBEs are composed of numerous entities, some studies also provide approaches to facilitate interoperability. These approaches consider messaging, business processes and collaboration protocol profile as layers to ensure DBE interoperability (Corallo, Caputo, \& Cisternino, 2007; Figay et al., 2012). While these insights are important, the relative newness of DBE requires continuous development and improvement of existing approaches until universal standards are achieved to enable seamless integration and interoperability between partners, services, processes and technologies.

\section{DBE conceptualisation theme}

Studies in this theme examine how the DBE concept has been envisioned. The axial codes under this theme are DBE development and management, DBE projects as well as DBE genesis and properties.

The DBE development and management sub-theme includes studies (e.g., Lurgi and Estanyol, 2010; Raza et al., 2009) that examine the formation, life cycle as well as evolution of DBEs. For instance, D'Andrea et al. (2013) propose a framework for the formation and management of a DBE through a three-stage approach: creation, monitoring and evaluation. Requirements for the creation stage include financial resources, value creation and sharing mechanism and strategic decisions on market, competitors and future insights. At the monitoring stage, requirements include quantifiable parameters, competitive assets, current roles and strategies as well as future trends. Lastly, the evaluation stage assesses the productive, robustness and niche creation capabilities. It is envisaged that if these requirements are fulfilled, issues concerning DBE formation and management can be handled. We see the discussions in this sub-theme as a useful contribution to the growth of DBE. However, more studies are required as dynamics in the DBE environment keep changing (Hu, Huang, Zeng, \& Zhang, 2016). 
Given that the DBE concept emerged from an EU project (Stanley \& Briscoe, 2010), some studies under the DBE conceptualisation theme examine key mandates and outcomes of the DBE project as well as the execution of related projects. These studies (e.g., Darking \& Whitley, 2007; Herdon et al., 2012) also discuss successes and challenges as well as replication of the DBE project in other European countries. For the most part, these studies provide an in-depth understanding of peculiar issues related to the execution of DBE projects. As such, the findings were largely policy driven. However, after completion of the EU DBE project, there has been arguably limited studies on post-implementation issues. It would be interesting to compare before and after implementation findings to know the overall success of the EU DBE project.

The last sub-theme is on DBE genesis and properties. Studies (e.g., Nachira et al., 2007; Stanley and Briscoe, 2010) in this sub-theme provide historical accounts of the DBE concept. These studies discuss the origin and emergence of DBE. Similarly, other studies (e.g., Briscoe et al., 2007) provide an overview and discuss the building blocks of DBE. Some of these studies are seminal articles that seek to provide general understanding of the DBE concept (Darking \& Whitley, 2007). A typical example is Stanley and Briscoe's (2010) study on the ABC of DBEs, which discusses the genesis, notion, overview, anatomy and building blocks. While the insights from these studies are useful, the focus has solely been on DBE without a thorough discussion of related concepts such as business ecosystem, collaborative network and innovation ecosystem. As a result, there is still some confusion in the literature as to the differences and similarities between DBE and related concepts.

\section{DBE artefacts theme}

Articles in this theme discuss artefacts in the form of methodologies, frameworks and modelling languages designed to support DBEs. The main motivation behind these artefacts is that the unique characteristics of DBE make application of existing artefacts unsuitable. The axial codes under this theme are DBE methodologies, DBE frameworks, DBE models and DBE modelling languages.

Articles on DBE methodologies provide systematic approaches applicable to certain issues such as agent interaction modelling methodology (Hussain et al., 2007d), DBE formation methodology (Nedbal, Brandtner, Auinger, \& Erskine, 2013) and trust failure detection methodology (Hussain et al., 2007b; 2007c). Similarly, articles on DBE frameworks present approaches that explain the underlying structure of issues in DBE. Examples of DBE frameworks include e-loyalty framework (Faed, 2010), process interoperability framework (Figay et al., 2012), reliability transaction processing framework (Adil et al., 2007) and feedback ontology framework (Adil, Hussain, Chang, Dillon, \& Ali, 2008).

The DBE models sub-theme includes articles that develop models as solutions to DBE issues. These models largely offer similar solutions as frameworks. Examples of the DBE models include trust model (Isherwood \& Coetzee, 2014), coordination model (Razavi, Moschoyiannis, \& Krause, 2007) and situation retrieval model (Lu, Niu, \& Zhang, 2013). Lastly, articles under the DBE modelling languages provide specific set of rules to express the blueprint of DBE objects. Some of the DBE modelling languages are the query meta- 
model language (Kotopoulos, Kazasis, \& Christodoulakis, 2007) and the business modelling language (Corallo et al., 2007).

While these artefacts are novel developments, they are largely conceptual. The majority of the artefacts lack empirical validation as they are derived from simulation data. In fact, some of the studies (e.g., Hussain et al., 2007a, 2007b; Lurgi \& Estanyol, 2010) themselves called for empirical validation of their artefacts. This study also supports these calls by prior research for empirical validation of DBE artefacts. We argue that through the validation, potential issues can be identified and appropriately addressed.

\subsection{Nature of methodologies and methods used in DBE research}

This subsection presents findings on methodologies and methods used in DBE research. The findings as presented in Table 3 addresses research question 2 (RQ2). We adapted Alavi and Carlson's (1992) research strategy classification framework during this analysis since it has extensive coverage of research methodologies and methods. The findings show that a large number of DBE research are conceptual in nature and therefore non-empirical (50.50\%). This situation is worrying because most of the conceptualisations are not tested to determine their applicability, efficacy and performance in practice. While this is worrying, a possible explanation could be the relative newness of DBE research and the difficulty in accessing empirical data. In terms of empirical studies, the simulation $(19.80 \%)$ and case study $(19.80 \%)$ methods are the widely used approaches under the qualitative and the quantitative methodologies. These approaches are followed by the interview (3.96\%), focus group $(3.96 \%)$ and survey $(1.98 \%)$ methods respectively. With regards to empirical studies, the result shows that DBE research favours qualitative approaches. One probable reason for the limited use of other quantitative methods is access to primary data from DBE participants. Thus, the case study method seems to be the most suitable option to access DBE data. In fact, most qualitative studies (e.g., Selander et al., 2010; Tan et al., 2009) have called for quantitative testing of their propositions.

Table 3 Research Methodologies and methods in DBE research

\begin{tabular}{llll}
\hline Research Classification & Research Methodologies and Methods & Count & Percentage \\
\hline Empirical & Quantitative & & \\
\hline & Survey & 2 & 1.98 \\
\cline { 2 - 4 } & Simulations & 20 & 19.80 \\
\cline { 2 - 4 } & Qualitative & 20 & 19.80 \\
\cline { 2 - 4 } & Case study & 4 & 3.96 \\
\cline { 2 - 4 } & Interview & 4 & 3.96 \\
\cline { 2 - 4 } & Focus group & 51 & 50.50 \\
\hline Non-Empirical & Conceptual Orientation & 101 & 100 \\
\hline Total & & & \\
\hline
\end{tabular}

\subsection{Nature of theories used in DBE research}

This subsection addresses research question 3 (RQ3) of this paper. With respect to theory, we examined the sampled papers to identify their theoretical underpinnings. The findings from the analysis as presented in Table 4 show that $72.27 \%$ of the publications did not use any theory. As such, we classified such articles under the "no theory" category. Among the articles that used theories, the Network theory recorded the highest usage of 3.96\%, followed 
by the Zachman framework (1.98\%), the Evolution (1.98\%) and the Social network theory $(1.98 \%)$. The rest of the theories such as Competing values theory, Resource-based theory, Ecological theory, Actor-network theory and Evolution theory each recorded $0.99 \%$.

The revelations from this analysis are that: (1) most DBE studies do not use theories and (2) DBE research lacks its own theories. These revelations could be attributed to the relative newness of the DBE concept. Also, the lack of DBE specific theorisation can be linked to heavy theory borrowing. Even though DBE is relatively new, it is still important for researchers to make the effort to build theories for significant contributions to the development of the research area.

Table 4 Theories used in DBE research

\begin{tabular}{lcc}
\hline Theories & Count & Percentage \\
\hline Architectural innovation theory & 1 & 0.99 \\
\hline Network theory & 4 & 3.96 \\
\hline Complexity theory & 1 & 0.99 \\
\hline Critical Mass theory & 1 & 0.99 \\
\hline Ecological theory & 1 & 0.99 \\
\hline Evolutionary Game theory & 1 & 0.99 \\
\hline Actor-network theory and Grounded theory & 1 & 0.99 \\
\hline Actor-network theory & 1 & 0.99 \\
\hline Activity Theory & 1 & 0.99 \\
\hline Hogg Model of Computational ecologies & 1 & 0.99 \\
\hline Markov chain theory & 1 & 0.99 \\
\hline Spectral graph theory & 1 & 0.99 \\
\hline Evolution theory & 2 & 1.98 \\
\hline Zachman framework & 2 & 1.98 \\
\hline Naturalistic decision-making model & 1 & 0.99 \\
\hline Competing values theory & 1 & 0.99 \\
\hline Boundary spanning practice & 1 & 0.99 \\
\hline Organisational Semiotics theory & 1 & 0.99 \\
\hline Social network theory & 2 & 1.98 \\
\hline Socio-technical multilevel framework & 1 & 0.99 \\
\hline TOE framework & 1 & 0.99 \\
\hline Claudio Ciborra's theory & 1 & 0.99 \\
\hline No theory & 73 & 72.27 \\
\hline Total & 101 & 100 \\
\hline & &
\end{tabular}

\section{Framework for DBE research}

This section presents our proposed framework to address research question 4 (RQ4). The framework serves as a bridge between existing and future DBE research by highlighting well and less researched issues. As a result, the framework provides a clear indication of the overall direction of DBE research. Moreover, this framework is a useful starting point for new researchers and practitioners to understand the current state of DBE research and identify areas that require further studies. With these insights, this framework is useful for academics and practitioners to obtain a snapshot of DBE research. The framework as presented in Figure 3 has three main components, namely research themes, methodologies 
and theories. These components detail the focus of prior DBE studies and future directions. For instance, the research theme component details the main issues in prior DBE studies. Similarly, the research methodologies and methods component show key approaches adopted in prior studies and the gaps future studies should consider. Lastly, the theories component presents the dominant theoretical lenses that have underpinned the extant DBE studies and avenues for future research. We elaborate on the framework by discussing gaps in DBE research themes, methodologies and theories that future studies may consider.

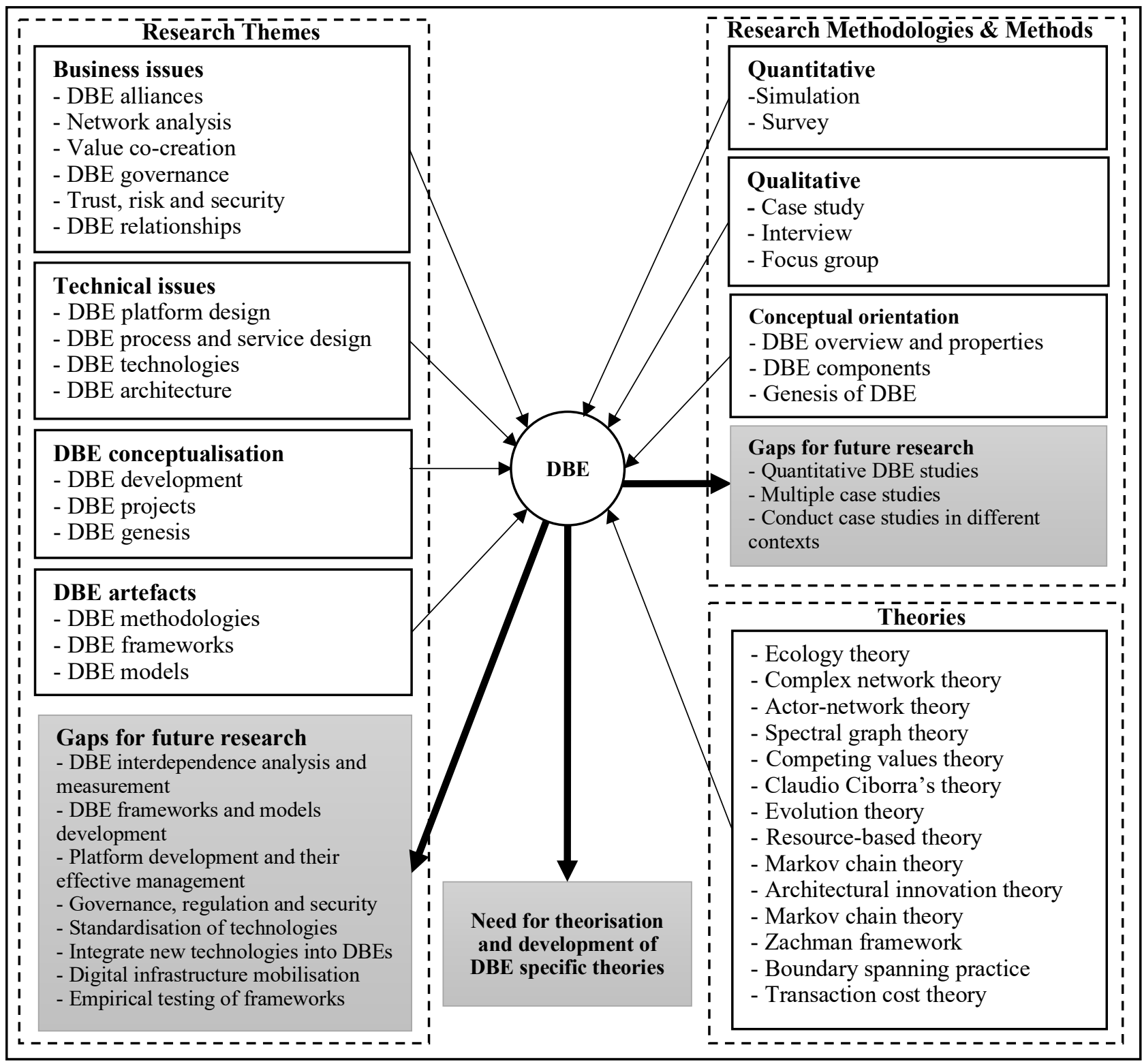

Figure 3. Framework for DBE research

\subsection{Gaps in DBE research themes for future studies}

While our framework acknowledges aspects of DBE research in some prior studies, we also point to fertile and under-researched areas for future studies. Indeed, we acknowledge that themes derived from prior DBE research have not been exhaustively researched. Thus, future studies can still explore some of these areas into detail. As presented in our framework, we have identified $8 \mathrm{key}$ gaps in DBE research themes for future studies. These gaps are as 
follows: (1) DBE interdependence analysis and measurement; (2) DBE frameworks, models and methodology development; (3) platforms development and their effective management; (4) governance, regulation and security; (5) standardisation of DBE technologies; (6) integrating new technologies into DBEs; (7) digital infrastructure mobilisation; and (8) empirical testing of frameworks, models and methodologies. We discuss each of these gaps in detail as follows.

First, we discuss the issue of DBE interdependence analysis and measurement. As presented in the DBE research framework in Figure 3, interdependence is one of the key issues investigated in prior studies. However, the extant DBE research has generally been investigated from relationships and network analysis perspectives. From the relationship standpoint, these studies examine how DBEs can be leveraged for enterprise agility (e.g., Tan et al., 2009) or how a firm transforms its DBE relationships to achieve an envisioned configuration (e.g., Selander et al., 2010). Though these studies provide antecedents to the nature of DBE relationships, the process of evaluating the impact of these relationships remains limited (Senyo et al., 2017; 2018). Similarly, studies that take the network analysis perspective usually engage in analysing the frequency of interactions, robustness, as well as links between partners based on physical and virtual relationships (e.g., Baggio \& Del Chiappa, 2014). Again, these studies do not provide mechanisms to measure the impact of interdependencies that underpin relationships in DBEs. As interdependence is fundamental to DBEs, its thorough analysis and measurement are important to research and practice. Hence, we argue that future research should consider investigating interdependence analysis and measurement in DBEs. For instance, future studies can develop metrics to measure social, operational and strategic impact of DBE interdependences in value co-creation.

Second, we point to the development of DBE specific frameworks, models and methodologies. From the analysis of prior studies presented in our DBE research framework, it was revealed that few artefacts have been developed. Some of these artefacts include process interoperability framework (Figay et al., 2012), DBE formation methodology (De Wilde \& Briscoe, 2011), trust failure detection methodology (Hussain et al., 2007c), DBE integration framework (Korpela et al., 2017, 2016) and process model for enterprise agility (Tan et al., 2009). While we acknowledge the insights provided by these artefacts, the current number is still limited, considering the growing demand for DBE solutions in practice. In addition, more DBE specific artefacts are needed to provide a solid foundation for future DBE studies. We also believe the application of these frameworks, models and methodologies in other academic fields will propel the growth of DBE research in general. Thus, we call for future studies to develop DBE specific artefacts such as frameworks, models and methodologies.

Third, we call for studies on platform development and its effective management. As presented in our framework, some studies examine how platforms support financial inclusion (Attour \& Peruta, 2014) while others investigate how platforms evolve into self-organising DBEs (Tan et al., 2016). Despite these insights, there are some aspects of DBE platforms that require further research. Specifically, a limited understanding exists on strategies for platform development and effective management (Sutherland \& Jarrahi, 2018). These aspects of DBE 
platform research have significant implications, especially for practitioners venturing into DBEs. Furthermore, there is limited knowledge on DBE platform development challenges and associated solutions. As sustainability of DBE platform is very important, there is a need for strategies to effectively manage DBE platforms after their launch. While most focal firms in DBEs own platforms, their usefulness is dependent on other partners. As such, it is important to understand how to strategically control platforms to the benefits of all participants (Koch \& Windsperger, 2017). Therefore, future research should recognise the potential in providing guidelines on the technical and business considerations in the development of DBE platforms as well as effective management strategies.

Fourth, our framework points to the need for studies on issues of governance, regulation and security due to the Internet-driven nature of DBEs. The issue of governance relates to maintenance of order in DBEs through, for instance, providing strategic direction, maintaining infrastructure as well as supporting participation (Darking et al., 2006). Though DBE is a self-organising entity, it still requires some level of control to maintain its balance. The key issues of concerns are how governance should be executed, who should constitute the governance structure, and what checks and balances exist (Darking et al., 2006). In terms of legislation, there is currently limited understanding of issues such as jurisdiction, applicable laws and judicial procedures for conflict resolution. Also, security is a major concern in DBEs due to the Internet-driven nature of operations and interaction between different participants from diverse geographical areas. Given that DBE embraces competition and collaboration, some participants are worried about the security of their corporate data. Currently, limited knowledge exists on some of these issues. Thus, future research should consider providing some guidelines and mitigation measures.

Fifth, our framework calls for studies on DBE technology standardisation. Currently, DBEs are powered by proprietary technologies. As a result, there are interoperability issues. A typical example is Apple's iOS and Google's Android operating systems. These are two different technologies that operate effectively in their respective DBEs but are not interoperable. As such, participants such as application developers find it difficult to transition seamlessly between the two DBEs. This situation places some constraints on participants, such as the requirement to use two different development kits for one application, hence, resulting in delays and increased operational cost. A possible solution to these issues is standardisation. We believe that if worldwide standards are agreed, problems of interoperability can be resolved (Korpela et al., 2016). Thus, future research call is made for studies to consider developing standards for DBE technologies to achieve worldwide uniformity.

Sixth, we expound on the issue of integrating new technologies such as business intelligence, data mining, machine learning, blockchain and partner recommender systems into DBEs (Korpela et al., 2017). DBE as a self-organising environment relies largely on its platforms during value co-creation. However, platforms are designed to perform specific tasks such as information sharing and process integration. As such, some emerging technologies that have significant capabilities are not initially designed with DBEs. But as DBEs continuously evolve, there is a need for them to use new technologies. In the DBE literature, limited 
guidelines and frameworks currently exist to provide directions on integrating emerging technologies. Thus, our DBE research framework calls for future studies on the development of a systematic guide to support the integration of emerging technologies.

Seventh, we discuss the issue of digital infrastructure mobilisation. DBEs rely on digital technologies and efforts from different participants to co-create value (Senyo et al., 2016). For instance, electronic payment service within a DBE will require digital infrastructure of banks, payment service providers such as VISA and MasterCard, as well as technologies of the sender and the receiver. This situation results in digital infrastructure mobilisation across DBEs. While this scenario looks simple in the illustration, in practice, it requires considerable systems integration among many partners. However, in the DBE literature, limited knowledge exists on how digital infrastructure can be mobilised from participants (Tan et al., 2016). Thus, the DBE research framework argues that researchers should recognise the potential of providing an understanding on the process of mobilising digital infrastructure.

Finally, we discuss the issue of empirical validation of developed DBE artefacts. While we argue for the development of DBE specific artefacts, it is also prudent to highlight the need for their empirical validation. In DBE research, there is currently a limitation in empirical testing of developed artefacts. In most cases, artefacts are tested with superficial data through simulation (e.g., Del Chiappa \& Baggio, 2015) and fictitious case studies (e.g., Hussain et al., $2007 \mathrm{c}$ ). Even though these validation approaches are closer to the real-world scenarios, they are conducted in controlled environments where uncertainties are not always accounted for. Thus, their application in the real-world may produce some errors. As such, it is important that DBE artefacts are tested with empirical data to address eventualities that may arise. Therefore, we support the calls from some extant studies (e.g., De Wilde \& Briscoe, 2011; Del Chiappa \& Baggio, 2015) for empirical validation of DBE artefacts.

\subsection{The role of methodology and method}

The findings from our analysis show that DBE research is dominated by conceptual oriented papers. On the contrary, there is limited use of quantitative and qualitative methodologies and methods in DBE research as presented in our framework in Figure 3. In most cases, studies that used quantitative and qualitative methodologies rely on simulation and case study methods. While all these insights are valuable, a further examination reveals the following issues. First, the dominant use of the simulation and the case study methods has resulted in limited utilisation of other approaches. Hence, future research should consider other methods such as survey and interviews. For instance, the use of surveys in future research will augment qualitative studies and support broader generalisations of findings. Indeed, in the extant DBE literature, some studies (e.g., Selander et al., 2010; Tan et al., 2009) have also called for alternative methods to test their propositions.

Second, most studies (e.g., Del Chiappa \& Baggio, 2015; Korpela et al., 2016; Tan et al., 2009) have used single cases. While results from a single case study are valuable, we call for future research to consider using multiple cases to strengthen generalisability of findings. In fact, some of the studies reviewed in this paper have called for multiple cases in future research. One of such studies is Tan et al (2009) which used a single case of Alibaba.com to 
inductively derive a process model for leveraging DBE for enterprise agility. Similar calls have been made by other studies (e.g., Korpela et al., 2016; Selander et al., 2010). As such, from our framework, we call on future studies especially the qualitative ones to consider multiple cases.

Finally, we discuss the issue of research study context. As presented in our framework in Figure 3, there is a need to conduct DBE research in other contexts since most existing studies have predominately been in the United Kingdom, Finland and Italy (e.g., Baggio and Del Chiappa, 2014; Korpela et al., 2017; Tsatsou et al., 2010; Whitley and Darking, 2006). Thus, globalisation of DBE research is limited. Hence, we challenge DBE researchers to consider other geographical contexts such as America, Africa, Australia, Asia and other parts of Europe in future studies. For instance, Baggio and Del Chiappa (2014) used a single case study in Italy to test a methodology on the inseparability of virtual and physical components in DBEs. For future research, the study calls for the application of their methodology in different geographical areas. Based on this and other calls, we believe that a context shift will create greater awareness, propel the growth of the DBE concept as well as generate greater interest from researchers all over the world. Thus, future DBE research should consider investigating less researched contexts as presented in our framework.

\subsection{The role of theory}

From our framework, there is a need for theorisation in DBE research as majority of existing studies have not utilised mainstream theories, models or frameworks except for a few (e.g., Darking \& Whitley, 2007; Koch \& Windsperger, 2017; Selander et al., 2010; Tan et al., 2016; Whitley \& Darking, 2006). Nevertheless, many of the theories used are borrowed from other disciplines. Even though theory borrowing is useful for the development of emerging research areas like DBE, it comes with some issues. First, there are issues of philosophical alignment between the original and the adapted context (Murray \& Evers, 1989). For instance, if the level of analysis of a theory originally focuses on individuals, using this theory in another context without cognisance to level sensitivity brings some philosophical problems. DBE embraces participation of multiple organisations from different industries; on the contrary, some theories focus on organisations in a single industry. Thus, the use of these theories may be problematic in DBE research because of philosophical misalignment (Whetten, Felin, \& King, 2009).

Furthermore, theory borrowing affects the maturity of research areas. While theory borrowing is important in undeveloped areas of research, the continuation of this practice can lead to stagnation of the borrowing field. Studies that borrow theories increase the maturity of the original field while the domain of application may remain immature. In fact, the results from our analysis point to the practice of large theory borrowing in DBE research. Thus, for the DBE field to grow into a well-established research area, there is a need for theory building efforts (Tan et al., 2016). In addition, we argue that theory building can lead to developing explanations for unique aspects of DBE that are perceived as difficult to understand. We also believe that theory building in DBE research will significantly contribute to new knowledge creation in the IS discipline at large. As such, we call for theorisation and DBE specific theory building as shown in our framework. 


\section{Conclusion}

In this paper, we conducted a systematic literature review to understand the state of DBE research and highlight potential areas for future research. As such, 4 research questions guided the study, namely: (1) What themes have been investigated in prior DBE research? What methodologies and methods have been utilised in the extant DBE research? What theories, models and frameworks have informed prior DBE research? What gaps exist in current DBE research that future studies can investigate?

In terms of the issues investigated in prior studies, our study reveals that DBE research can be categorised into 4 main themes, namely business issues, technical issues, DBE conceptualisation and DBE artefacts (see Table 2). From these main themes, the business issues dominated the others. Next, our findings also reveal that extant DBE research has utilised some theories, which are mostly borrowed from other academic fields. Further, the findings also point to the dominant use of qualitative methodology and case study method in the extant DBE research while the use of quantitative methodology remains limited. However, this review shows that a large number of DBE studies are conceptual in nature with little empirical validation.

While ecosystem research in the broad management field is increasing, DBE studies, on the other hand, is dwindling. This is evident in the number of DBE publications over the years. The paucity of DBE research can be attributed to a number of reasons. First is the difficulty to access data from multiple participants, making DBE research a daunting task. Second is the lack of clear understanding of the DBE concept. In some cases, DBE is literally equated with related concepts such as innovation and business ecosystem. Lastly, the completion of the EU DBE project has resulted in limited funding for more research. While the decreasing DBE research trend is worrying, it also presents a unique opportunity for some journals to take a leadership role and become pacesetters for others as DBE continues to gain increasing popularity in practice. Though DBE research is difficult to undertake, ongoing changes in the traditional value chain place huge responsibilities on researchers to provide the needed understanding and develop new business models to support organisations.

By unearthing the findings pointed above, this study makes the following contributions. First, it develops a framework that synthesises the extant studies and provides gaps for future DBE research (see Figure 3). Our study is arguably the first to provide a complete synthesis of DBE research over the years. As such, it provides a clear indication of the overall direction of DBE research. With this direction, this study serves as a foundation for future DBE research by revealing knowledge gaps for further investigations. Second, this study contributes by pointing out theoretical and methodological trends in DBE research. Third, the use of grounded theory literature review method in this study moves our review a step further from some existing ones to enable a holistic literature coverage and thorough analysis for advancing knowledge. Thus, future reviews can follow this study as a guide to operationalise the grounded theory literature review method. Lastly, this study contributes to the understanding of the DBE concept by clearly delineating its components, properties and characteristics. We envisage the discussions in this article to rekindle debates and draw new researchers to push forward the development of DBE research. Two key limitations of our 
review are the subjective approach of deriving the DBE research themes and our focus on themes, methodologies and theories. As such, future studies can employ objective methods such as scientometrics, bibliometrics, or main path analysis to review studies on DBE to augment our research.

\section{References}

Acharya, A., Singh, S. K., Pereira, V., \& Singh, P. (2018). Big data, knowledge co-creation and decision making in fashion industry. International Journal of Information Management, 42, 90-101. https://doi.org/10.1016/j.ijinfomgt.2018.06.008

Adil, H., Hussain, F. K., Chang, E., Dillon, T. S., \& Ali, S. (2008). Ontological framework for trust \& reputation for DBE. In International Conference on Digital Ecosystems and Technologies (pp. 650-653). Phitsanulok, Thailand. https://doi.org/10.1109/DEST.2008.4635204

Adil, H., Saqib, A., \& Fei, L. (2007). A reliable transaction processing framework for digital business ecosystems. In International Conference on Digital Ecosystems and Technologies (pp. 275-280). Cairns, Australia.

Adner, R. (2006). Match your innovation strategy to your innovation ecosystem. Harvard Business Review, 84(4), 98-107. https://doi.org/Article

Alavi, M., \& Carlson, P. (1992). A review of MIS research and disciplinary development. Journal of Management Information Systems, 8(4), 45-62.

Attour, A., \& Peruta, M. Della. (2014). Architectural knowledge: key flows and processes in designing an inter-organisational technological platform. Knowledge Management Research \& Practice, 14(1), 27-34. https://doi.org/10.1057/kmrp.2014.21

Baggio, R., \& Del Chiappa, G. (2014). Real and virtual relationships in tourism digital ecosystems. Information Technology and Tourism, 14(1), 3-19. https://doi.org/10.1007/s40558-013-0001-5

Briscoe, G., Sadedin, S., \& Paperin, G. (2007). Biology of Applied Digital Ecosystems. In International Conference on Digital Ecosystems and Technologies (pp. 458-463). Cairns, Australia.

Burford, S., \& Resmini, A. (2017). Cross-channel information architecture for a world exposition. International Journal of Information Management, 37(6), 547-552. https://doi.org/10.1016/j.ijinfomgt.2017.05.010

Camarinha-Matos, L. M., \& Afsarmanesh, H. (2008). Collaborative networks: Reference modeling. Springer Science \& Business Media.

Cheah, C. (2007). The emperor's new clothes: Redressing digital business ecosystem design. In International Conference on Digital Ecosystems and Technologies (pp. 602-606). Cairns, Australia.

Chou, E. Y., Lin, C. Y., \& Huang, H. C. (2016). Fairness and devotion go far: Integrating online justice and value co-creation in virtual communities. International Journal of Information Management, 36(1), 60-72. https://doi.org/10.1016/j.ijinfomgt.2015.09.009

Chuang, S. H., \& Lin, H. N. (2015). Co-creating e-service innovations: Theory, practice, and impact on firm performance. International Journal of Information Management, 35(3), 277-291. https://doi.org/10.1016/j.ijinfomgt.2015.01.002

Corallo, A., Caputo, E., \& Cisternino, V. (2007). Business modelling language: A framework supporting interoperability in cluster of SMEs. In International Conference on Digital Ecosystems and Technologies (pp. 107-112). Cairns, Australia. https://doi.org/10.1109/DEST.2007.371954

Corbin, J. M., \& Strauss, A. (1990). Grounded theory research: Procedures, canons, and evaluative criteria. Qualitative Sociology, 13(1), 3-21. https://doi.org/10.1007/BF00988593

D'Andrea, A., Ferri, F., Grifoni, P., \& Guzzo, T. (2013). Digital eco-system: The next 
generation of business services. In International Conference on Management of Emergent Digital EcoSystems (pp. 40-44). Neumünster Abbey, Luxembourg.

Darking, M., Dini, P., \& Whitley, E. E. (2006). The challenge of building public technology infrastructure: issues of governance and sustainability in a digital business ecosystem. In European Conference on Information Systems (pp. 1-9).

Darking, M., \& Whitley, E. (2007). Towards an understanding of FLOSS: infrastructures, materiality and the digital business ecosystem. Science Studies, 20(2), 13-33.

De La Rosa, J. L., Hormazábal, N., Aciar, S., Lopardo, G. A., Trias, A., \& Montaner, M. (2011). A negotiation-style recommender based on computational ecology in open negotiation environments. IEEE Transactions on Industrial Electronics, 58(6), 20732085. https://doi.org/10.1109/TIE.2009.2027917

De Wilde, P., \& Briscoe, G. (2011). Stability of evolving multiagent systems. IEEE Transactions on Systems, Man, and Cybernetics, Part B: Cybernetics, 41(4), 11491157. https://doi.org/10.1109/TSMCB.2011.2110642

Del Chiappa, G., \& Baggio, R. (2015). Knowledge transfer in smart tourism destinations: Analyzing the effects of a network structure. Journal of Destination Marketing \& Management, 4(3), 145-150. https://doi.org/10.1016/j.jdmm.2015.02.001

Faed, A. (2010). A conceptual framework for E-loyalty in digital business environment. In International Conference on Digital Ecosystems and Technologies (pp. 547-552). Dubai, United Arab Emirates. https://doi.org/10.1109/DEST.2010.5610594

Fayoumi, A. (2016). Ecosystem-inspired enterprise modelling framework for collaborative and networked manufacturing systems. Computers in Industry, 80, 54-68. https://doi.org/10.1016/j.compind.2016.04.003

Figay, N., Ghodous, P., Khalfallah, M., \& Barhamgi, M. (2012). Interoperability framework for dynamic manufacturing networks. Computers in Industry, 63(8), 749-755. https://doi.org/10.1016/j.compind.2012.08.008

Fischer, R., Scholten, U., \& Scholten, S. (2010). A reference architecture for feedback-based control of service ecosystems. In International Conference on Digital Ecosystems and Technologies (pp. 1-6). Dubai, United Arab Emirates. https://doi.org/10.1109/DEST.2010.5610624

Gartner. (2015). Predicts 2015: Enterprise Architects Refocus on Digital Business Ecosystem.

Graça, P., \& Camarinha-Matos, L. M. (2017). Performance indicators for collaborative business ecosystems - Literature review and trends. Technological Forecasting and Social Change, 116, 237-255. https://doi.org/10.1016/j.techfore.2016.10.012

Herdon, M., Várallyai, L., \& Péntek, Á. (2012). Digital business ecosystem prototyping for SMEs. Journal of Systems and Information Technology, 14(4), 286-301. https://doi.org/10.1108/13287261211279026

Hu, H., Huang, T., Zeng, Q., \& Zhang, S. (2016). The role of institutional entrepreneurship in building digital ecosystem: A case study of Red Collar Group (RCG). International Journal of Information Management, 36(3), 496-499. https://doi.org/10.1016/j.ijinfomgt.2015.12.004

Hussain, O. K., Chang, E., Hussain, F., \& Dillon, T. (2007a). Quantifying the level of failure in a digital business ecosystem interactions. In International Conference on Emerging Technologies and Factory Automation (pp. 818-825). Patras, Greece. https://doi.org/10.1109/EFTA.2007.4416864

Hussain, O. K., Chang, E., Hussain, F. K., \& Dillon, T. S. (2007b). A methodology to quantify failure for risk-based decision support system in digital business ecosystems. Data \& Knowledge Engineering, 63(3), 597-621. https://doi.org/10.1016/j.datak.2007.03.014

Hussain, O. K., Chang, E., Hussain, F. K., \& Dillon, T. S. (2007c). A methodology to quantify failure for risk-based decision support system in digital business ecosystems. 
Data Knowledge Engineering, 63(3), 597-621. https://doi.org/10.1016/j.datak.2007.03.014

Hussain, O. K., Chang, E., Hussain, F. K., \& Dillon, T. S. (2007d). Quantifying the loss in resource benefit for risk based decision in digital business ecosystem. In International Conference on Internet and Web Applications and Services (pp. 2917-2922). Morne, Mauritius. https://doi.org/10.1109/ISIE.2007.4375077

Isherwood, D., \& Coetzee, M. (2014). TrustCV: Reputation-based trust for collectivist digital business ecosystems. In Annual Conference on Privacy, Security and Trust (pp. 420424). Toronto, Canada. https://doi.org/10.1109/PST.2014.6890970

Kamboj, S., Sarmah, B., Gupta, S., \& Dwivedi, Y. (2018). Examining branding co-creation in brand communities on social media: Applying the paradigm of Stimulus-OrganismResponse. International Journal of Information Management, 39, 169-185. https://doi.org/10.1016/j.ijinfomgt.2017.12.001

Koch, T., \& Windsperger, J. (2017). Seeing through the network: Competitive advantage in the digital economy. Journal of Organization Design, 6(1), 6. https://doi.org/10.1186/s41469-017-0016-z

Korpela, K., Hallikas, J., \& Dahlberg, T. (2017). Digital Supply Chain Transformation toward Blockchain Integration. In Hawaii International Conference on System Sciences (pp. 4182-4191). https://doi.org/http://hdl.handle.net/10125/41666

Korpela, K., Mikkonen, K., Hallikas, J., \& Pynnonen, M. (2016). Digital business ecosystem transformation - Towards cloud integration. In Hawaii International Conference on System Sciences (pp. 3959-3968). https://doi.org/10.1109/HICSS.2016.491

Kotopoulos, G., Kazasis, F., \& Christodoulakis, S. (2007). Querying MOF repositories: The design and implementation of the Query Metamodel Language (QML). In International Conference on Digital Ecosystems and Technologies (pp. 373-378). Cairns, Australia. https://doi.org/10.1109/DEST.2007.372001

Li, Y.-R. (2009). The technological roadmap of Cisco's business ecosystem. Technovation, 29(5), 379-386. https://doi.org/10.1016/j.technovation.2009.01.007

Lu, J., Niu, L., \& Zhang, G. (2013). A situation retrieval model for cognitive decision support in digital business ecosystems. IEEE Transactions on Industrial Electronics, 60(3), 1059-1069. https://doi.org/10.1109/TIE.2012.2188253

Lurgi, M., \& Estanyol, F. (2010). Managing a digital business ecosystem using a simulation tool. In International Conference on Management of Emergent Digital EcoSystems (pp. 213-220). Bangkok, Thailand. https://doi.org/10.1145/1936254.1936295

Marcon, G., Okada, H., Heistracher, T., Corallo, A., \& De Tommasi, M. (2008). Software engineering within a dynamic digital business ecosystem. International Journal of Business Process Integration and Management, 3(4). https://doi.org/10.1504/IJBPIM.2008.024981

Moore, J. F. (1993). Predators and prey: a new ecology of competition. Havard Business Review, 71(3), 75-83.

Moore, J. F. (1996). The Death of Competition: Leadership and Strategy in the Age of Business Ecosystems. New York: Harper Business.

Murray, J. B., \& Evers, D. J. (1989). Theory borrowing and reflectivity in interdisciplinary fields. Advances in Consumer Research, 16(1), 647-652.

Nachira, F., Dini, P., \& Nicolai, A. (2007). A network of digital business ecosystems for Europe: roots,processes and perspectives. In Digital Business Ecosystem. European Commission Information Society and Media.

Ndou, V., Schina, L., Passiante, G., Del Vecchio, P., \& De Maggio, M. (2010). Toward an open network business approach. In International Conference on Digital Ecosystems and Technologies (pp. 282-287). Dubai, United Arab Emirates. https://doi.org/10.1109/DEST.2010.5610632

Nedbal, D., Brandtner, P., Auinger, A., \& Erskine, M. A. (2013). The Critical Mass in 
Collaborative Digital Business Ecosystems for Innovation. In International Conference on Digital Ecosystems and Technologies (pp. 96-101). Menlo Park, USA.

Pappas, N., Kazasis, F. G., Anestis, G., Gioldasis, N., \& Christodoulakis, S. (2007). A knowledge management platform for supporting digital business ecosystems based on P2P and SOA technologies. In International Conference on Digital Ecosystems and Technologies (pp. 196-202). Cairns, Australia. https://doi.org/10.1109/DEST.2007.371970

Peltoniemi, M. (2006). Preliminary theoretical framework for the study of business ecosystems. Emergence: Complexity \& Organization, 8(1), 10-19. https://doi.org/10.1007/s11252-006-0005-4

Petrou, M., \& Giannoutakis, K. N. (2009). Modeling buyer-seller relations in a closed system of shared resources, incorporating personal preference and trust. IEEE Transactions on Systems, Man, and Cybernetics Part A:Systems and Humans, 39(5), 1035-1050. https://doi.org/10.1109/TSMCA.2009.2025046

Prahalad, C. K., \& Ramaswamy, V. (2004). Co-creating unique value with customers. Strategy \& Leadership, 32(3), 4-9. https://doi.org/10.1108/10878570410699249

Presenza, A., Micera, R., Splendiani, S., \& Del Chiappa, G. (2014). Stakeholder einvolvement and participatory tourism planning: Analysis of an Italian case study. International Journal of Knowledge-Based Development, 5(3), 311-328. https://doi.org/10.1504/IJKBD.2014.065320

Raza, M. B., Kirkham, T., Harrison, R., Monfared, R. P., Haq, I., \& Wood, S. (2009). Evolving knowledge based product lifecycle management from a digital ecosystem to support automated manufacturing. In International Conference on Management of Emergent Digital EcoSystems (pp. 437-441). Lyon, France. https://doi.org/10.1145/1643823.1643904

Razavi, A. R., Moschoyiannis, S. K., \& Krause, P. J. (2007). A Coordination Model for Distributed Transactions in Digital Business EcoSystems. In International Conference on Digital Ecosystems and Technologies (pp. 159-164). Cairns, Australia. https://doi.org/10.1109/DEST.2007.371963

Selander, L., Henfridsson, O., \& Svahn, F. (2010). Transforming Ecosystem Relationships in digital innovation. In International conference on Information Systems (pp. 1-15). St. Louis, USA.

Selander, L., Henfridsson, O., \& Svahn, F. (2013). Capability search and redeem across digital ecosystems. Journal of Information Technology, 28(3), 183-197. https://doi.org/10.1057/jit.2013.14

Senyo, P. K., Addae, E., \& Boateng, R. (2018). Cloud computing research: A review of research themes, frameworks, methods and future research directions. International Journal of Information Management, 38(1), 128-139. https://doi.org/10.1016/j.ijinfomgt.2017.07.007

Senyo, P. K., Liu, K., \& Effah, J. (2017). Towards a Methodology for Modelling Interdependencies between Partners in Digital Business Ecosystems. In IEEE International Conference on Logistics, Informatics and Service Sciences (pp. 11651170). Kyoto.

Senyo, P. K., Liu, K., \& Effah, J. (2018). A Framework for Assessing the Social Impact of Interdependencies in Digital Business Ecosystems. In K. Liu, K. Nakata, W. Li, \& C. M. C. Baranauskas (Eds.), Digitalisation, Innovation and Transformation (pp. 132-143). Reading: Springer. https://doi.org/10.1007/978-3-319-67774-3_19

Senyo, P. K., Liu, K., Sun, L., \& Effah, J. (2016). Evolution of norms in the emergence of digital business ecosystems. In M. Baranauskas, K. Liu, L. Sun, V. Neris, R. Bonacin, \& K. Nakata (Eds.), Socially Aware Organisations and Technologies. Impact and Challenges (pp. 79-84). Springer, Cham. https://doi.org/10.1007/978-3-319-42102-5_9

Stanley, J., \& Briscoe, G. (2010). The ABC of Digital Business Ecosystems. 
Communications Law - Journal of Computer, Media and Telecommunications Law, 15(1), 1-24.

Sun, L., Tan, C., Robertson, S., Liu, K., Cook, M., \& Collins, C. (2016). Open Digital Business Ecosystems: A Pathway for Value Co-creation. In International Conference on Informatics and Semiotics in Organisations (pp. 85-94). Campinas, Brazil.

Sutherland, W., \& Jarrahi, M. H. (2018). The Sharing Economy and Digital Platforms : A Review and Research Agenda. International Journal of Information Management, 43, 328-341. https://doi.org/10.1016/j.ijinfomgt.2018.07.004

Svirskas, A., Ignatiadis, I., \& Briggs, J. (2008). Agent-based service-oriented collaborative architecture for value chains of SMEs. In International Conference on Digital Ecosystems and Technologies (pp. 161-167). Phitsanulok, Thailand. https://doi.org/10.1109/DEST.2008.4635158

Tan, B., Pan, S. L., Lu, X., \& Huang, L. (2009). Leveraging Digital Business Ecosystems for Enterprise Agility: The Tri-Logic Development Strategy of Alibaba . com. In International conference on Information Systems (pp. 1-18). Phoenix, USA.

Tan, F., Pan, S., \& Liu, J. (2016). Towards a Self-Organizing Digital Business Ecosystem: Examining IT-Enabled Boundary Spanning Practice of China's LeEco. In International conference on Information Systems (pp. 1-12). Dublin, Ireland.

Tan, Y. L., \& Macaulay, L. (2011). Factors Affecting Regional SMEs Progression to Digital Business Ecosystems. In Americas Conference on Information Systems (pp. 1-12). Detroit, USA.

Tsatsou, P., Elaluf-calderwood, S., \& Liebenau, J. (2010). Towards a taxonomy for regulatory issues in a digital business ecosystem in the EU. Journal of Information Technology, 25(3), 288-307. https://doi.org/10.1057/jit.2009.22

Vargas, A., Cuenca, L., Boza, A., Sacala, I., \& Moisescu, M. (2016). Towards the development of the framework for inter sensing enterprise architecture. Journal of Intelligent Manufacturing, 27(1), 55-72. https://doi.org/10.1007/s10845-014-0901-z

Vargo, S. L., Maglio, P. P., \& Akaka, A. M. (2008). On value and value co-creation: A service systems and service logic perspective. European Management Journal, 26(3), 145-152. https://doi.org/10.1016/j.emj.2008.04.003

Wang, J., De Wilde, P., \& Wang, H. (2009). Topological analysis of a two coupled evolving networks model for business systems. Expert Systems with Applications, 36(5), 95489556. https://doi.org/10.1016/j.eswa.2008.07.090

Webster, J., \& Watson, R. T. (2002). Analyzing the Past to Prepare for the Future: Writing a Literature Review. MIS Quarterly, 26(2), xii-xxiii.

Whetten, D. A., Felin, T., \& King, B. G. (2009). The Practice of Theory Borrowing in Organizational Studies: Current Issues and Future Directions. Journal of Management, 35(3), 537-563. https://doi.org/10.1177/0149206308330556

Whitley, E. A., \& Darking, M. (2006). Object lessons and invisible technologies. Journal of Information Technology, 21(3), 176-184. https://doi.org/10.1057/palgrave.jit.2000065

Wolfswinkel, J. F., Furtmueller, E., \& Wilderom, C. P. M. (2013). Using grounded theory as a method for rigorously reviewing literature. European Journal of Information Systems, 22, 45-55. 